\title{
FACTORIAL VALIDITY OF THE DESCRIPTIVE/INJUNCTIVE NORM PREFERENCE SCALE
}

\author{
Norihiro Kuroishi ${ }^{1}, \&$ Yoriko Sano ${ }^{2}$ \\ ${ }^{1}$ Institute for Educational Research and Service, International Christian University (Japan) \\ ${ }^{2}$ College of Interhuman Symbolic Studies, Kanto Gakuin University (Japan)
}

\begin{abstract}
This study was the second report of developing the Descriptive/Injunctive Norm Preference Scale. This scale intended to measure individual differences in personal attitudes against social norms. Cialdini et al. (1991) distinguished social norms into two types. Descriptive norm is decided by what behavior most people engage in a particular situation, which is reflected in perceived typicality. Injunctive norm, on the other hand, is defined by habits or moral rules, which represents what people approve/disapprove. This study was a part of the process to develop the scale that assess the tendency how people prefer to obeying/violating descriptive/injunctive norms. The pilot study created 90 items inquiring ones' attitudes (cognition, affection, and behavior) toward descriptive/injunctive norms.

Previous exploratory factor analysis (EFA) extracted 3 factors from the selected 56 items out of the pilot scale; F1: Apprehension of deviance from descriptive norms, F2: Regard for injunctive norms, and F3: Aversion to injunctive norms. This study tried to replicate the factor structure, and to examine the construct validity of the scale. Participants were recruited anew from a research company panel, and 400 hundred adults (200 females and 200 males) responded to online questionnaires. Confirmatory factor analysis (CFA) indicated the goodness of fit to be fair to the 3-factor model hypothesized from a priori analysis. Further verification in comparison with other related psychological constructs would be needed to examine its content validity.
\end{abstract}

Keywords: Scale development, factorial validity, injunctive and descriptive norms.

\section{Introduction}

Social norms influence an individual's behaviors. According to Cialdini et al. (1991), social norms can be distinguished into two types. Descriptive norm is decided by what most people do in a particular situation, which may bring about perceived typicality. On the other hand, injunctive norm is defined by moral rules, which reflects what people approve/disapprove. In many cases, these types of norms agree with each other. People recognize thieving as vice, and most people do not engage in such a misdeed. In some cases, however, descriptive norms can conflict with injunctive norms. Although people think they should not litter in public places, rubbish on the ground may indicate that many people litter habitually. When the two types of norms are disparate, the descriptive norms have greater effects on individuals' behaviors than the injunctive norms do.

Our previous research tried to reveal affective states when people obey/violate social norms, and showed that Japanese people feel calmer and have less negative affects when they follow descriptive norms. These tendencies seemed to be robust across demographic and cultural backgrounds. Exploration of genders, age-groups, and some other individual differences such as individualism-collectivism, need for uniqueness, and fear of success, indicated that these factors were irrelevant to the affective states. Only a within-subject examination revealed that rejection sensitivity moderate the affective reactions to social norms (Kuroishi \& Sano, 2017).

This study was the second step to develop a scale that directly assess the individual differences in how people prefer to obeying/violating descriptive/injunctive norms, and tried to examine the factorial validity of the scale by a confirmatory factor analysis (CFA). 


\section{Methods}

\subsection{Measure}

Fifty-five items were selected from the items used in the pilot study (Kuroishi \& Sano, 2018). The items were originally generated according to the original Cialdini's theory, and referred to cognition, emotion, or behavior when people obey or violate descriptive/injunctive norms.

Table 1. Standardized Factor Loadings Estimated by Confirmatory Factor Analysis (CFA).

\begin{tabular}{|c|c|c|c|}
\hline Item Details & F1 & $\mathrm{F} 2$ & $\mathrm{~F} 3$ \\
\hline I want to do the same with everyone. & .789 & & \\
\hline It is embarrassing unless I do the same behavior as the surroundings. & .731 & & \\
\hline I am worried about whether I behave differently from the surrounding people. & .718 & & \\
\hline I'd like to do the same thing as everyone. & .727 & & \\
\hline I want to do the same by looking at the behavior of people around me. & .798 & & \\
\hline I am careful not to get out of what everyone is doing. & .724 & & \\
\hline I am worried that I am not doing the same thing as everyone else. & .734 & & \\
\hline I am relieved that I am doing the same as the surrounding people. & .753 & & \\
\hline I want to adopt what many people do. & .762 & & \\
\hline I am too embarrassed to behave in the different way from others. & .680 & & \\
\hline I am concerned about being out of touch with other people. & .774 & & \\
\hline I feel nervous when I am different from other people. & .715 & & \\
\hline I act like people around me before I know it. & .761 & & \\
\hline It is better to tailor to the behavior many people do. & .735 & & \\
\hline I am okay when I follow the things people do. & .736 & & \\
\hline I cannot stop looking at what everybody is doing. & .644 & & \\
\hline I feel quite safe when keeping the same behavior as other people. & .741 & & \\
\hline I often behave like the surrounding people at first. & .778 & & \\
\hline It is safe to obey the major opinion, even though it is different from my own opinion. & .671 & & \\
\hline It is better to do in concert with everyone. & .700 & & \\
\hline I am concerned about the state of the surrounding people. & .721 & & \\
\hline Apart from my opinions, it is better to behave in the same way as everyone. & .706 & & \\
\hline I look down on those who behave differently from everyone. & .540 & & \\
\hline I often slip my eyes attracted towards behaviors of the surrounding people. & 619 & & \\
\hline I don't want to act out of the surroundings. & .769 & & \\
\hline I try to keep rules and regulations. & & .756 & \\
\hline It is better to keep rules. & & .778 & \\
\hline Rules are important for everyone to live comfortably. & & .759 & \\
\hline I want to act socially appropreate. & & .784 & \\
\hline It is natural to observe rules. & & .781 & \\
\hline It is not good to break rules. & & .746 & \\
\hline I feel anger for those who do not follow rules. & & 677 & \\
\hline It is not good to ignore customs and customs. & & .513 & \\
\hline I want to make rules so that confusion will not occur. & & 617 & \\
\hline I feel guilty when in breaking rules and regulations. & & .662 & \\
\hline An old custom has some meaning. & & .527 & \\
\hline There are many customs which do not fit the present era. & & .406 & \\
\hline There are some worthless rules. & & .425 & \\
\hline I am relieved when under rules and regulations. & & 680 & \\
\hline I feel uneasy when I don't keep rules and regulations. & & 639 & \\
\hline Rules and regulations are not necessary for our lives. & & -.336 & \\
\hline I am sensitive to the rule and the regulation to protect. & & .572 & \\
\hline I do not want to obey customs and traditions. & & & .719 \\
\hline I am not concerned about customs and traditions. & & & 679 \\
\hline Traditions and customs are stuffy. & & & 659 \\
\hline I don't want to be tied down with customs. & & & .614 \\
\hline I don't want to be bound by rules. & & & .560 \\
\hline I don't like to behave in the same way as everyone else. & & & .491 \\
\hline I don't like customs or traditions. & & & .718 \\
\hline It does not matter whether I can follow customs and traditions. & & & .676 \\
\hline I don't mind even if I break customs and traditions. & & & .637 \\
\hline I don't care about customs and traditions. & & & .672 \\
\hline I really hate rules and regulations. & & & .542 \\
\hline I feel stressed in observing rules and regulations. & & & .509 \\
\hline $\begin{array}{l}\text { One should carry the opinion once he/she believe to be right, even though contrary to } \\
\text { the public convention. }\end{array}$ & & & .506 \\
\hline
\end{tabular}




\subsection{Data collection}

Web questionnaire survey was applied in this study. Four-hundred Japanese of the panel who have registered with Neo Marketing Inc. participated in our study. Respondents were planned to be obtained equally from 4 demographic groups; genders (males and females) x age-groups (aged 20-39 and 30-59). Data were collected successfully, and the sample consisted of 100 younger males (aged 33.35), 100 older males (aged 51.02), 100 younger females (aged 32.76), and older female (aged 48.85). Participants got access to the website and completed the questionnaire with agreement with providing their data for the study.

\subsection{Procedure}

Respondents were asked to read the statements about descriptive/injunctive norms carefully, and decide how they agree to each opinion on 5-point rating from "strongly disagree" (1) to "strongly agree" (5). The items were randomly displayed to each respondent.

\section{Results and Discussion}

Preliminarily, an exploratory factor analysis (EFA) by maximum likelihood extraction and with a promax rotation was conducted. Three-factor solution was adopted according to the pilot study. All the items loaded the most by the expected factor. The factor structure of the pilot data was replicated by the current data.

Mainly, a confirmatory factor analysis (CFA) indicated the goodness of fit to be fair to the goodness of fit to the 3-factor model which was hypothesized from the pilot study (RMR=.070, and RMSEA $=.068,90 \%$ CI $[.065, .070]$ ). Table 1 showed the standardized factor loadings. The factors were interpreted as the pilot study; F1 Apprehension of deviance from descriptive norms, F2 Regard for injunctive norms, and F3 Aversion to injunctive norms.

The inter-factor correlation coefficients were $r_{F 1-F 2}=.367, \quad r_{F 2-F 3}=-.142$, and $r_{F 3-F 1}=.117$, respectively. The significance of the coefficients suggested the only correlation between F1 and F2, and simple structures among other pairs of the factors.

\section{Conclusions}

These results manifested the factorial validity the Descriptive/Injunctive Norm Preference Scale (DINPS). This study validated the robustness and the goodness of fit to the hypothesized 3-factor structure of the items. It might indicate the feasibility to assess how people prefer to obeying/violating descriptive/injunctive norms, and predict the tangible behaviors people adopt to descriptive/injunctive norms.

There is, however, plenty of room for improvement. First, this scale is needed to verify its construct validity with comparing to the relevant psychological concepts: For examples, authoritarian personality (F-scale: Adorno et al., 1950) for a tendency to obey injunctive norms, and need for uniqueness (Snyder \& Fromkin, 1980) for a tendency to violate descriptive norms. Second, the original scale is in Japanese, and it is needed to develop some versions in other language such as English to examine its cross-validity. These attempts will enable international comparative studies across cultures.

\section{References}

Adorno, T. W., Frenkel-Brunswik, E., Levinson, D. J., \& Sanford, R. N. (1950). The Authoritarian Personality. New York: Harper and Row.

Cialdini, R. B., Kallgren, C. A., \& Reno, R. R. (1991). A focus theory of normative conduct. Advances in Experimental Social Psychology, 24, 201-234.

Kuroishi, N. \& Sano, Y. (2017). A within-subject study of affective reactions to social comparisons by considering individual differences in need for uniqueness and rejection sensitivity. Comprehensive Studies of Education: Journal of Japan Professional School of Education, 10, 63-79.

Kuroishi, N. \& Sano, Y. (2018.05) Development of a descriptive/injunctive norm preference scale. Poster Presentation at the International Psychological Applications Conference and Trends 2018.

Snyder, C. R., \& Fromkin, H. L. (1980). Uniqueness: The human pursuit of difference. New York: Plenum Press. 